\title{
RITUAL, SCHECHNER E PERFORMANCE
}

\author{
Regina Polo Müller \\ Universidade Estadual de Campinas - Brasil
}

\begin{abstract}
Resumo: $O$ artigo trata da experiência realizada no estágio pós-doutoral com Richard Schechner no Departamento de Estudos da Performance da Tisch School of the Arts/ New York University, abordando a natureza da pesquisa desenvolvida pela autora, seus antecedentes e desdobramentos. O objetivo é apresentar de modo biográfico resultados da pesquisa e do processo de criação em performance realizados com o apoio das teorias da performance de Victor Turner e Richard Schechner. A pesquisa compreendeu trabalho de campo como observadora participante do processo de criação e montagem da peça teatral YokastaS, dirigida por Schechner. A criação pela autora de uma performance apresentada em Congresso científico é abordada como a etapa final de um percurso de transformações e passagens como pretende considerar o estágio realizado, visando caracterizar um fazer antropológico construído através de depoimentos da experiência pessoal.
\end{abstract}

Palavras-chave: antropologia da performance, performance, ritual e teatro, Schechner.

\begin{abstract}
The article is about the author's experience in the pos-doctoral studies in the Performance Studies Department of Tisch School of the Arts/NYU with Richard Schechner, approaching the kind of research developed by the author, its antecedents and what was unfolded from it. The aim is to present, in biographic way, the results of the research and the process of creation in performance accomplished with the theoretical approach from Richard Schechner and Victor Turner. The research included the fieldwork as participant observer on the production process of the play YokastaS directed by Schechner. The creation of a performance exhibited by the author in a scientific meeting is considered as the last step of a transformation path and passageways as she considers her studies in USA were in order to have an anthropological work built through the researcher's own experience.
\end{abstract}

Keywords: anthropology of performance, performance, ritual and theatre, Schechner. 
Nova Iorque, 5 de abril de 2003. Em relatório do estágio pós-doutoral na New York University, departamento de Performance Studies da Tisch School of the Arts, eu dizia que o "desejado aprofundamento da metodologia de trabalho artístico do professor Richard Schechner encontrou condições que se revelaram fundamentais para a obtenção de resultados da pesquisa”, superando as expectativas com relação ao plano de trabalho estabelecido inicialmente. Nesse plano, de acordo com a sugestão do professor, eu pretendia participar do curso "Ritual, Play, and Performance”, ministrado por ele, e, na medida do possível, participar de workshops por ele dirigidos, tendo como objetivo aprofundar o conhecimento e discutir, tendo este autor como interlocutor, sua metodologia de criação em artes cênicas. Ocorreu que, paralelamente aos estudos teóricos, passei a realizar trabalho de campo tornando-me observadora participante do processo de criação, sob sua direção, da peça YokastaS, encenada no teatro La MaMa. Tive a oportunidade de experienciar, desde o início, em novembro de 2002, o processo de criação e de preparação dos intérpretes, bem como assistir às apresentações públicas, algumas vezes participando como contra-regra. Meu papel no grupo, e o crédito no material de divulgação, entretanto, foi o de observadora (observer), também referida como antropóloga/ observadora (anthropologist/observer).

As categorias descritivas e analíticas da reflexão teórica que Schechner (1973, 1982, 1985, 1988, 1994, 2002) faz a respeito de sua obra, construídas por ele próprio, se encontram na intersecção entre as ciências humanas, a estética e a biologia. Sua estreita relação com a antropologia, bem como suas inspirações e diálogos com a psicanálise, filosofia e biologia constituem o referencial teórico básico. Este largo espectro de teorias clássicas e contemporâneas sobre ritual e play se organiza em torno dos conceitos de performance e performatividade, uma das principais contribuições teóricas de Schechner.

No curso "Ritual, Play, and Performance”, eu estudava os conceitos, o referencial teórico que possibilitaria compreender melhor a obra de Schechner, cuja contribuição aos estudos da performance foi construída a partir de uma reflexão sobre a relação entre ritual e teatro. No ano de 2002, ele havia lançado o livro Performance Studies, an Introduction (Schechner, 2002), no qual apresenta as fontes teóricas de sua tese sobre as relações entre ritual, play e performance, tema do curso e desdobramento de suas pesquisas mais recentes. Ao mesmo tempo, este último livro é apresentado em formato didático, com exercícios e sugestões de leitura para a pesquisa, produto de uma das dimensões profissionais de meu interlocutor. Dentre suas inúmeras atividades, 
a de professor e formador de pesquisadores representa uma interessante e importante faceta. Talvez, entretanto, não aquela que ame preferencialmente.

Assisti também a seu curso "Experimental Performance, 1960s-Present (mostly USA)", que trazia, antes de mais nada, uma excelente etnografia das artes cênicas nos Estados Unidos na segunda metade do século XX. Não poderia ter havido modo mais fértil de fazer o levantamento das produções e experiências cênicas que compreendem o contexto em que a metodologia de Schechner se desenvolveu, como havia me proposto realizar no projeto de pesquisa.

Farto material documental audiovisual (vídeo e fotografia) foi apresentado nos cursos, parte pertencente ao arquivo pessoal e parte à da Bobster Library (New York University). Nesse segundo curso, o pesquisador considerou o período em questão como de grande crescimento da performance experimental, quando surge um novo gênero - a arte da performance (performance art). Ao mesmo tempo, segundo Schechner, antigos gêneros foram reconcebidos e reestruturados, podendo-se constatar, atualmente, que o teatro convencional ocupa apenas uma faixa na variada gama de novas abordagens que então surgiram e tiveram continuidade até os dias de hoje, nas quais se conectam as artes, os rituais, as ações político-sociais e as comunidades locais.

Assisti ainda a seminários sobre The Performance Group, do qual ele foi um dos fundadores e diretor, The Wooster Group, originado de uma dissidência do primeiro, por iniciativa de uma de suas principais atrizes, Elizabeth LeCompte, e o Squat Theater, este último com a participação no seminário de um de seus membros, Klara Plotai. Foi, entretanto, a leitura do livro que Schechner escreveu em 1971-72 sobre o que chamou de "practice of environmental theatre" (Schechner, 1973), vivida de 1967 a 1980, incluindo a experiência no The Performance Group, que me colocou as principais questões que orientaram o trabalho de campo sobre a montagem de YokastaS, realizada 30 anos depois. $\mathrm{Na}$ verdade, essa leitura não somente produziu questões de pesquisa como também despertou fascínio sobre uma trajetória que eu passava a conhecer através de farta documentação, depoimento e análise do próprio sujeito das experiências em pauta. E, ainda, eu estava tendo a oportunidade de participar de uma delas, sentindo-me muito privilegiada por, desse modo, realizar um verdadeiro mergulho na obra daquele "guru whose principles and influence have survived a quarter-century of reaction and debate": é desse modo que o autor do livro é mencionado na contracapa da nova edição ampliada de Environmental Theatre (Schechner, 1994), espécie de "bíblia de uma nova geração de artistas de teatro”, também segundo a mesma apresentação. Entre este livro, para 
artistas, e o mais recente, para estudiosos da performance (Schechner, 2002), se descortinava para mim toda uma vida e obra artística e intelectual que eu testemunhava agora, a partir de uma espécie de síntese, curiosa por comparar o guru dos anos 1960-1970 ao professor cujo trabalho de diretor tomou o rumo da produção artística aliada ao ensino e pesquisa acadêmica. Os dilemas da criação coletiva, do papel do diretor e suas relações com os atores, da improvisação e rigor técnico e estético, do texto dramatúrgico e texto performático, do lugar do corpo e do espaço entre os atores e o público, do engajamento político e apego à tradição do teatro antigo (os clássicos gregos), estavam no primeiro livro, e agora eu os via (e vivia com o grupo), como num papel de investigador vigilante da herança do guru Richard Schechner.

Eu havia chegado até ele através de Victor Turner, quer dizer, das leituras de suas últimas obras (Turner, 1982, 1988), que construíram a antropologia da performance, parte da antropologia da experiência, segundo ele próprio. Esta proposição teórico-metodológica de Turner está alicerçada no drama como analogia da vida social e na ponte entre o ritual e o teatro, percurso que contou com a companhia de Schechner no final dos anos 1970, início dos anos 1980. Escreve Turner (1982, p. 7):

The essays in this book chart my personal voyage of discovery from traditional anthropological studies of ritual performance to a lively interest in modern theatre, particularly experimental theatre.

Turner escreveu From Ritual to Theatre (1982) e Schechner escreveu From Ritual to Theatre and Back (1988).

Eu também tenho sido artista e antropóloga. Formada na USP e Unicamp e atriz de um grupo de teatro surgido no movimento da contracultura em São Paulo nos anos 1970, o Dzi-Croquettes, estudei as sociedades indígenas e desenvolvi meu corpo decorado em performance como meio de expressão. Produzi teses antropológicas profissionalmente e apresentei performances como lazer, após uma tentativa frustrada de viver de teatro. O que consegui fazer foi uma antropologia para atores e dançarinos, quando ingressei na carreira docente universitária. Por conta dessa migração da etnologia indígena para o ensino e pesquisa em dança, encontrei um caminho para fazer esta ponte em Turner, aquele mesmo de Floresta de Símbolos (2005) e O Processo Ritual (1974) de minha formação antropológica. Conheci este outro Turner, por sua vez, através de Geertz (1993) que representava, nesse momento, minha moti- 
vação para a reconciliação com a teoria antropológica. Estivera até então, em meus trabalhos de interpretação da dança nos rituais dos Asuriní do Xingu e de danças de religiosidade popular no interior de São Paulo, apoiada na análise do discurso da escola francesa. ${ }^{1}$ Em Geertz (1983, p. 31), na analogia do texto como configuração da teoria social, o conceito de "inscrição", a fixação do sentido, é a chave para a transição da escrita como discurso para a ação como discurso. Esse conceito de "inscrição" diz respeito à contextualização histórico-social do discurso, ou seja, a relação entre discurso e as condições de produção de sentido (Müller, 1993). Eu estava preocupada nessas pesquisas com a noção de persistência do significado da ação em geral (Geertz, 1983, p. 31). E, através de um enfoque interdisciplinar, passei a cotejar as formulações deste autor às da análise do discurso, no caso, a fixação de sentido e a tensão constitutiva entre o novo e o tradicional, entre a variação (polissemia) e o sedimentado (paráfrase), na produção do discurso. A proposta metodológica da análise do discurso está inscrita na perspectiva da enunciação (na lingüística) que, por sua vez, se relaciona a orientações recentes do campo das ciências humanas. Na lingüística, um de seus precursores é Bakhtin, que considera a relação com o outro o fundamento da discursividade. As reflexões desse autor dizem respeito ao "princípio dialógico", isto é, ao caráter constitutivo da interação enunciativa. Para ele, a natureza da linguagem é fundamentalmente dialógica, ou seja, a linguagem é enunciação e a enunciação é basicamente social. Ou seja, a substância da língua é o fenômeno social da interação verbal (dialogia) realizada através da enunciação (Bakhtin apud Müller, 1998, p. 274). O processo da enunciação é uma atualização temporal e espacial do sujeito em seu discurso. Pela teoria da enunciação não se analisa, pois, o texto realizado como um produto, mas se procura refletir sobre o ato de produção desse texto. Tratava-se, a meu ver, da noção de "inscrição" de sentido a que se refere Geertz ao apresentar a analogia do texto na antropologia contemporânea. Na antropologia interpretativa de Geertz e na antropologia da experiência de Turner encontrei uma perspectiva de interdisciplinaridade entre ciências humanas e ciências sociais, as quais consideram a dimensão estética e sensível da experiência social e permitem a contextualização cultural do significado. Suas obras examinam justamente a performance teatral e a do ritual. Do diálogo entre os dois,

\footnotetext{
Estou me referindo particularmente a teóricos da análise do discurso, como Michel Pêcheux, Dominique Maingueneau, Eni Orlandi.
}

Horizontes Antropológicos, Porto Alegre, ano 11, n. 24, p. 67-85, jul./dez. 2005 
sobre dilemas da analogia do drama para a vida social como referência teórica para as questões metodológicas da pesquisa em artes cênicas, fui me direcionando, conduzida por Turner, a aprofundar a teoria da performance e a metodologia de criação artística de Richard Schechner como diretor. Assim, em 2001, eu escrevia a ele sobre meus interesses e, uma vez recebida como visiting scholar no departamento onde leciona e aceita como pesquisadora de sua obra, logo tive a oportunidade de pedir para conhecer sua atuação artística. Eu desejava conhecer o diretor de teatro, o "guru" do teatro experimental americano que havia iniciado Victor Turner (1982, p. 9, 10). Diziam no departamento de Performance Studies que de modo diferente do que ocorrera comigo, em geral ali se chegava a Turner através de Schechner.

Grande parte de meus colegas de cursos eram atores e dançarinos. Entre eles, havia também excelentes performers, e Marina Abramovic esteve numa atividade coletiva do departamento, conversando sobre a performance que havia apresentado na época em Nova Iorque, The House with the Ocean View.

Em uma das aulas do curso sobre as teorias da performance, "Ritual, Play, and Performance”, cujo título no programa era "Ritual and Play Compared. A Neurological Perspective on Ritual”, Schechner ministrou um workshop que chamou de "Experiencing Light Trance", para o qual devíamos estar vestidos para dançar (ao lado do título da aula lia-se a observação "come dressed to dance"). A participação neste workshop representou o primeiro passo de realização do verdadeiro projeto que me levava para fora do país e para este contexto acadêmico-artístico em particular. Minha intenção verdadeira, para além daquela expressa acima no relatório para a agência financiadora, foi viver um período de reclusão e rito de passagem para uma nova fase profissional e pessoal. Afastada do cotidiano de trabalho e de meu meio-ambiente, viver entre os americanos significaria experiência semelhante à vivida entre os Asuriní do Xingu, o contato e comunicação com o outro que nos leva a refletir sobre nós próprios e acionar processos de transformação e redefinição de identidade.

Nesse ambiente de artistas e pesquisadores e tendo Schechner como anfitrião, senti-me pronta para a travessia. Livre de compromissos estabelecidos por outros - agora a livre-docência permitia a liberdade da autodeterminação , estranha em outra cultura de modo a ganhar igualmente a liberdade de agir como um diferente, sentia-me muito à vontade para me comportar segundo minhas próprias buscas. Schechner pedia para nos vestirmos com roupa leve, modo adequado para o trabalho corporal que desenvolveria conosco, isto é, exercícios de respiração e movimentos de dança em grupo. Eu fui com todos 
os colares que havia trazido comigo, um grande volume de peso. O uso de um monte de colares pelas mulheres asuriní nas danças rituais sempre me intrigou. Se a proposta do workshop era a de explorar o estado de transe provocado pelo movimento e respiração realizados pela execução da dança, eu tinha para mim um laboratório para testar o estado das Asuriní do Xingu ao dançarem, e, portanto, obter experiência semelhante com um elemento diverso da proposta de meu "adviser" americano. Em lugar da leveza, o peso. Em lugar do corpo à vontade, carregar quilos de contas que potencializam o peso da gravidade, a puxada do corpo para o chão. Eu experimentava juntar a experiência da memória do corpo na aldeia indígena com a do corpo na cidade de Nova Iorque, ambas na situação de reclusão e suspensão de minha vida regular. Schechner apenas perguntou se eu iria participar daquele modo e eu expliquei meu objetivo, dizendo que pretendia experimentar um "light trance” à moda das mulheres asuriní. Esta experiência seria retomada no terceiro passo de minha passagem por este portal, imagem que eu atribuía simbolicamente aos estudos em Nova Iorque.

Sobre esta relação entre a vida com os Asuriní do Xingu e a estada nos Estados Unidos, escrevi em um dos relatórios sobre o processo de criação e encenação de YokastaS que, durante o trabalho de campo com o grupo teatral, eu freqüentemente o comparava com a experiência de pesquisa entre os índios. Destacando as semelhanças, propunha então nesse estudo tratar dos seguintes temas: 1) o ritual indígena e o dia-a-dia na aldeia e as sessões de montagem e exibições da peça e o viver em Nova Iorque; 2) a relação com o “outro” na situação de pesquisa e a experiência existencial (viver num meio cultural diferente do pesquisador); 3) o crescimento pessoal: viver entre os índios e entre os americanos, participando de seus rituais; 4) a língua, a comunicação, os canais de percepção.

O segundo passo importante que tornaria aquele estágio pós-doutoral uma experiência iniciática foi me integrar ao grupo de teatro da East Company of Artists, de Richard Schechner, na montagem da peca YokastaS. Sua atuação nessa companhia representa talvez, esta sim, a realização de um de seus objetivos mais caros, o de formar e estimular jovens atores de diversas tendências e formações artísticas, num encontro profícuo de diferenças, catalisado por sua incrível energia de levar à frente seus experimentos.

Convidada por ele a participar do grupo desde a primeira reunião de atores, produtores, assistentes de direção e dramaturgos, em resposta ao meu pedido de conhecer sua atuação artística, fui apresentada como antropóloga/ 
observadora. A partir de então, tornei-me, segundo depoimento posterior ${ }^{2}$ de um dos atores, o olhar deles sobre si próprios. $\mathrm{O}$ fato de serem observados por alguém que não expressava comentários ou reações, porque estava ali para observar, criava uma situação de reflexividade na qual o ator podia preencher $\mathrm{o}$ vazio de uma observação silenciosa com aquilo que imaginava que eu estivesse sentindo e interpretando. Era um olhar que estava sempre ali, acompanhando tudo o que acontecia, distante pelo silêncio, mas, ao mesmo tempo, muito próximo pela intimidade criada pelo encontro quase diário e com os exercícios de ioga, compartilhamento corporal e sensorial, respiração e contato físico. Eu apenas me pronunciava quando interpelada pelo diretor, cuja proposta de criação do texto e interpretação nos laboratórios incluía a presença de público em todas as sessões. Eu era o público cativo, outros convidados eram alunos dos cursos, professores do departamento, professores convidados, figurinista, iluminador, produtor, etc.

Não se fizeram uma só vez laboratórios e ensaios sem público. E, em todos, Schechner pedia a opinião dos que os assistiam. O processo de work in progress, como ele próprio definia o trabalho com o grupo, consistia em laboratórios conduzidos, inicialmente, através de técnicas projetadas por Schechner em torno da idéia de “corpo emocional”. E, fundamentalmente, através dos textos produzidos por ele e por Saviana Stanescu, escritora dramaturga romena, os quais eram reescritos a duas mãos, a partir dos laboratórios.

Pude observar inicialmente, e era minha expectativa pelas leituras de seus livros, particularmente Environmental Theatre (Schechner, 1994), osse dada mais ênfase ainda a essas técnicas durante todo o processo, técnicas que, a partir de estímulos imagéticos, textuais, sonoros, poéticos e psicofísicos, promoviam a construção do "cavalo”, “médium” ou ator, integrada à construção dos personagens. Por minha expectativa, Schechner daria ênfase ao corpo na construção do texto dramatúrgico e cênico, pois atribui a ele o "começo e o fim de toda atuação performática: "All performing work begins and ends in the body.” (Schechner, 1973, p. 132). A ação do corpo nos processos de treinamento do ator cênico recebeu diversas interpretações e métodos de realização nas artes cênicas contemporâneas, como o orientalismo incorporado às técni-

\footnotetext{
2 Após as apresentações públicas, final dessa etapa dos trabalhos da ECA com YokastaS, a atividade seguinte de minha pesquisa foi entrevistar todos os atores, cujos depoimentos foram gravados e constituem parte do material etnográfico.
}

Horizontes Antropológicos, Porto Alegre, ano 11, n. 24, p. 67-85, jul./dez. 2005 
cas de treinamento do teatro experimental americano, como se via nos exercícios de ioga que abriam todas as sessões, inclusive o aquecimento antes da apresentação pública. Assim, na criação de YokastaS encontrava-se essa marca de ênfase na ação corporal, mas, efetivamente, o lugar estruturante da criação dramatúrgica coube ao texto. Em confronto e/ou dialogando com a dimensão corporal e expressiva, o tema desenvolvido literariamente pelos autores provocava a criação e desenvolvimento de personagens e sua interpretação, o que, por sua vez, oferecia material para a reescritura e criação do texto em coautoria. Entre, de um lado, as improvisações nos laboratórios estimuladas pelo texto e, de outro, a direção de Schechner sobre a interpretação dos atores e marcação das cenas, a dinâmica do processo de montagem de YokastaS apresentou duas fases: a primeira, dos workshops de treinamento físico relacionados aos laboratórios de improvisação, e os próprios laboratórios, fontes de material para a escritura da peça, e a segunda, de encenação da mesma sob direção de Schechner. Com essa passagem de uma fase à outra, pude observar certa tensão entre os atores. Havia momentos de resistência por parte deles, e as muitas mudanças no texto e, conseqüentemente, nas marcações e na direção de interpretação, eram causa de descontentamento. Em entrevistas que fiz posteriormente com os atores, a esse descontentamento quanto à relação entre eles e o diretor, preocupado então em estabelecer o frame, a estrutura cênica, o score, somava-se certa decepção quanto ao que esperavam - e eu acrescento, idealizavam - a respeito da proposta artística do "guru” do teatro experimental americano. Como concluí no estudo realizado (Müller, 2003, p. 203),

[...] contrariando a expectativa por parte do público e dos atores, o texto e sua encenação sob uma direção constituíram a estrutura da proposta [...] a principal novidade residiria na importância do texto, particularmente na sua estrutura que representaria as bases da proposta estética atual que reproduz, ao mesmo tempo, os princípios da obra experimental de Richard Schechner.

Transcrevo aqui outros trechos de minha interpretação, na tentativa de buscar compreender os "30 anos nesta peça” e reencontrar nosso "guru”:

Compreendi, no final, que, neste caso, não se tratava de desconstrução para se obter a construção, a partir da ação e da experiência sensorial e corpórea do ator, mas da intertextualidade entre as duas dimensões, o texto e a performance, com as contradições e confrontos constitutivos deste processo. Utilizando conceitos do próprio Schechner (1982, p. 29), compreendi que a ênfase maior seria dada ao 
"texto dramatúrgico" (“dramatic text”) e não ao "texto da performance” ("performance text"), o verdadeiro "score" a partir do qual a experiência de "flow" em "playing" poderia ser vivenciada pelos atores que, desse modo, levariam também o público a compartilhar do teatro como um ritual de transformação. E, como na acepção do ritual enquanto experiência reflexiva, residiria na performance de uma estrutura, ou seja, na participação dos membros da comunidade de atores e de espectadores - no caso destes, manifesta ou não - o meio pelo qual a arte pode realizar esta experiência. (Müller, 2003, p. 200).

Sobre a estrutura do "texto performativo" como chamei o script final de Stanescu e Schechner, escrevi:

Durante as apresentações no teatro La MaMa, a partir do resultado final (texto e encenação), obtido na fase anterior, os atores continuaram a construir os personagens, experimentando ser YokastaS e seu parceiro. E deste modo, conseguindo mais ou menos, um dia sim, outro nem tanto, provocar posicionamento do público sobre sua própria experiência enquanto protagonistas da situação apresentada. Este desfecho foi obtido pela multiplicidade do personagem e pelo final sem fim e aberto do texto e encenação. (Müller, 2003, p. 202).

Finalmente, para apresentar como hipótese dessa interpretação um princípio fundamental da atuação de Schechner como autor e diretor, na verdade uma dica dada pelo próprio, digo que com YokastaS ele "pretendeu ir tão longe quanto possível no seu objetivo de se divertir com o processo, isto é, estar sempre ensaiando, estar sempre em situação de ensaio, estar sempre 'playing"” (Müller, 2003, p. 202).

Produzi esse texto ainda em Nova Iorque, como também dei início a um trabalho de criação em performance, o terceiro passo de minha travessia. Este começaria com um pé em Nova Iorque, outro em Campinas e o próximo no 51ํㅜㅇ Congresso Internacional dos Americanistas, em Santiago do Chile, em julho de 2004.

O tema de um dos simpósios desse congresso para o qual fui convidada a participar, “Arte, Música e Globalização na América Latina” e a sugestão, no convite das organizadoras, de se apresentar uma peça musical ou teatral a um público ávido por "anthro-performances”, mais a inspiração para “me divertir com o processo”, foram os estímulos para eu colocar em prática o desejo de uma transformação nos meus estudos sobre os Asuriní do Xingu e na minha relação com o mundo acadêmico. 
Desde o início de minha convivência com os Asuriní do Xingu, ouvi muitas vezes o convite para dançar, "sazaha oforahai”, nos rituais que realizavam para trazer os espíritos à aldeia e vivenciar os eventos cosmogônicos da origem dos tempos. Nunca dancei a noite toda, nos três dias seguidos de um "maraká", ritual xamanístico de cura e de propiciação para garantir a caça e a colheita. Apenas uma vez, no ritual cosmogônico "turé”, consegui participar durante toda uma noite, incumbida que fora de encarnar a função/personagem mítico da kavarivandara, a mulher que acompanha Kavara, o guerreiro sobrevivente, o duplo do eu na unidade do ser humano vivo, indivisível (Müller, 1990, p. 109, 272).

Paramentada com os ornamentos, colares e pulseiras, bandoleiras e cintos de miçangas, coco, contas e dentes de macaco, penugem de gavião na cabeça e pernas e tinta de jenipapo cobrindo todo o corpo, consegui chegar ao final do rito do "kavara", do choro aos mortos, junto à grande panela japepaí, no centro da casa comunal.

Foi pouco para quem viveu, muitas e muitas vezes, a situação de ser convidada insistentemente a dançar para agradar aos espíritos. Foi insignificante para quem foi convidada pelos Asuriní do Xingu para participar desse momento de instauração do momento cosmogônico de se encarnar, na vivência ritual, o "isso e aquilo", o ser humano e o ser mítico.

Dancei muito pouco, perante as inúmeras vezes em que as mulheres me ofereciam a prazerosa atividade de compartilhar o canto e o movimento coletivo de corpos se abraçando, ao som e ritmo do iafu, o chocalho do xamã, ou do avai'ip, o bastão de percussão da mulher xamã, ou, ainda, da melodia e ritmo das clarinetas turé. Eu deveria ter dançado muito mais.

A performance que eu desejei realizar para o Congresso dos Americanistas estaria baseada nessa memória e no encontro com formas de manifestação da cultura nativa do continente norte-americano, no contexto da multiculturalidade e da demanda comercial do mercado mais radicalmente marcado pela globalização. Assim, foram diversas as razões pelas quais a música dos índios cree chegaram a mim no processo de criação. Antes, porém, de explicar isso, é necessário falar como esse processo foi desencadeado, o que nos leva a outra marca da experiência multicultural vivida no âmbito do mundo ocidental, mais particularmente norte-americano e mais ainda, das artes da performance nos Estados Unidos: a presença das técnicas corporais do oriente incorporadas nas décadas de 60 e 70 no teatro e dança. Estou falando dos exercícios de ioga que precediam as sessões de laboratórios e ensaios da montagem de YokastaS. Nos últimos 12 anos, minha pesquisa sobre ritual entre os Asuriní do Xingu, iniciada em 1976, desdobrou-se na investigação da dança no ritual indígena e 
sua relação com a performance contemporânea. Assim, no estudo do processo de criação desenvolvido pela metodologia de Richard Schechner, eu trazia, além do método da antropologia, a experiência de ter pesquisado rituais indígenas. Observava, por exemplo, que algumas práticas desse teatro americano são ritualizadas, produto da experiência de Schechner nas pesquisas que realizou sobre rituais na Ásia e entre várias sociedades “nativas” ou “aborígenes” e, ao mesmo tempo, na sua profissão como diretor teatral na tradição experimental. Nesses momentos, no processo de encenação desenvolvido por Schechner, criava-se, ou pretendia-se criar, o sentimento de "communitas” (Turner, 1974, 1982), retirando os atores do cotidiano e levando-os para o plano dos sonhos e fantasias. Esse processo é realizado através da condição de playing e é dirigido por uma estrutura. No caso dos rituais em sociedades tradicionais, essa estrutura é encontrada em sua cosmologia e mitologia. No teatro, a atividade de playing está baseada na estrutura que é representada pelo script, o tema, a narrativa dramatúrgica. São a atividade de playing e o caráter processual do ritual e das artes cênicas que permitem sua comparação e a conceituação de ambos como "performance cultural" (Singer apud Turner, 1988, p. 21). Por outro lado, dentre as linguagens das artes cênicas, é a performance a que mais se aproxima, a meu ver, da experiência ritual nas sociedades indígenas. A reelaboração e atualização dos conteúdos dos rituais indígenas no contexto histórico corresponde, na experiência artística contemporânea ocidental da performance, à elaboração subjetiva do ator performático. Ele propõe à audiência, com seu script dramatúrgico, o mesmo exercício de reflexividade sobre a realidade, através da experiência estética. Citando Turner (1988, p. 22),

[...] if the contrivers of cultural performances, whether these are recognized as individual authors, or wether they as representatives of a collective tradition, genuises or elders, hold the mirror up to nature, they do this with "magic mirrors" which make ugly or beautiful events or relationships which cannot be recognized as such in the continuous flow of quotidian life in which we are embedded. These mirrors themselves are not mechanical, but consist of reflecting consciousness and the products of such consciousnesses formed into vocabularies and rules, into metalinguistics grammars, by means of which new unprecedented performances may be generated.

A escolha da linguagem da performance para participar do simpósio sobre arte e globalização, tendo como objeto de reflexão a dança entre os Asuriní do Xingu, povo indígena da Amazônia, partiu assim de uma experiência de pesqui- 
sa teórico-prática. Eu propunha também nesses estudos cotejar a metodologia de Schechner à de Graziela Rodrigues, pesquisadora em dança brasileira, cujos pontos em comum podem ser salientados. Para Rodrigues (1997), o processo de formação do bailarino intérprete e criador ocorre ao se penetrar manifestações populares brasileiras que contenham o sentido de resistência cultural, relacionando-o com realidades onde a devoção vivida pelo corpo é uma habilidade de sobreviver como ser humano. A convivência com essa realidade promove a experiência de ruptura, através da qual se constrói a linguagem do corpo em sua relação com a história, a identidade e o inconsciente coletivo. No processo que Rodrigues propõe desenvolver a criação e a interpretação em dança, encontra-se igualmente a "transformação/transportação" e a conjunção entre preparação técnica, laboratório e ensaio referidos por Schechner (1985) ao cotejar os dois gêneros de "performance cultural", o ritual e a arte da performance, através da convergência entre o vivido pelo artista performático e pelo iniciando no ritual. Segundo este autor, tanto na performance cênica artística quanto no ritual, o padrão processual implica em separação, transição e incorporação, citando as fases da iniciação ritual para Van Gennep (apud Schechner, 1985, p. 20). Usando suas categorias, Schechner considera o preparo técnico, o laboratório e o ensaio como ritos preliminares, de separação. A performance em si é a liminaridade, análoga aos ritos de transição. O relaxamento e o retorno são pós-liminaridade, ritos de incorporação. Através dessas fases, acentuadamente marcadas, as pessoas iniciadas no ritual sofrem transformação permanentemente, enquanto que nas performances, de um modo geral, as transformações são temporárias. Schechner as denomina, então, "transportações". Para ele, como as iniciações, as performances fazem de uma pessoa, outra. Mas diferentemente das iniciações, completa, "performances geralmente tratam daquilo que o performer recobra de seu próprio eu" (Schechner, 1985, p. 20, tradução minha). No processo desenvolvido pela metodologia de Graziela Rodrigues, pesquisa de campo e laboratório desembocam numa personagem a ser "incorporada" (a liminaridade nesse caso pode corresponder ao que denomina "incorporação" da personagem, a performance em si, e a transformação/transportação de que fala Schechner). No processo de desenvolvimento da personagem, o primeiro sujeito a ser pesquisado pelo bailarino é ele mesmo, tal como a autora relata:

Tendo como princípio a "estrutura física”, o corpo-sentido é sistematicamente trabalhado. Procura-se atingir, a nível profundo, os ossos e músculos envolvidos 
em cada matriz de movimento. Esta associação às imagens internas provoca sensações distintas em cada pessoa. O desdobramento das temáticas, provindas das manifestações culturais pesquisadas, é realizado a partir da incorporação de seus campos simbólicos, considerando-se as dinâmicas específicas de cada uma delas. Estas fontes provocam um conflito no bailarino, levando-o a questionar sua Identidade. Estes conflitos são vistos como importantes elementos nas linguagens da dança, já que os seus movimentos são trabalhados. O percurso interior (imagens e registros emocionais) é desenvolvido em interação com o movimento exterior, buscando-se sempre uma qualidade que seja resultante da realidade do sujeito-bailarino. (Rodrigues, 1997, p. 147).

A pesquisa de campo que venho realizando desde 1976 entre os Asuriní do Xingu me proporcionaria a experiência corporal e a memória de uma "estrutura física” a ser trabalhada na criação da performance que trataria justamente da questão de minha identidade na convivência com eles e da subjetividade da experiência estética no contexto intercultural. Eu me propus a refletir sobre o tema do simpósio a partir da experiência do pesquisador, construindo esse personagem como texto performático a ser apresentado à audiência, formada por outros pesquisadores, e com ele suscitar a discussão. Pretendi propor uma forma de produzir conhecimento no contexto acadêmico e antropológico, em particular, de modo a responder ao desafio proposto pelas organizadoras do simpósio.

Assim, eu tinha a pesquisa em andamento na New York University e a experiência de viver a dança entre os Asuriní do Xingu como ponto de partida para criar a “anthropo-performance”, título tomado do termo “anthroperformance”, como as organizadoras do simpósio denominaram outras formas possíveis de apresentação dos trabalhos. Tinha também uma sala na Tisch School of the Arts, no número 721 da Broadway, sexto andar, e tempo para ficar dançando o quanto quisesse ou pudesse. Nessa sala, assisti aos cursos de Richard Schechner e aos ensaios da peça YokastaS. Nessa sala, participei dos exercícios de ioga, no aquecimento dos laboratórios e ensaios. Nessa sala, iriam se misturar o viver entre os Asuriní do Xingu e entre os americanos, observando e participando de suas “performances culturais”. O corpo da ioga e o corpo da dança asuriní iriam se misturar como movimento, cujas matrizes associadas à imagem interna e registro emocional, provocariam a incorporação da personagem.

No primeiro laboratório, iniciei a sessão com exercícios de ioga e, na seqüência do exercício final de respiração, o som do “om” se transformou no som 
do canto das mulheres asuriní acompanhando o xamã no ritual do "maraká". Outra referência ou dado da memória, nesse caso, recente, foi o workshop "Experiencing Light Trance", ou o primeiro passo da travessia em curso, como o chamei e descrevi acima. Sete meses depois, quando dei início ao processo de criação da "anthropo-performance" e o som do canto das mulheres asuriní veio do "om" da prática indiana da ioga, tive como certo que eu dançaria do modo como dancei no workshop: com todos os colares que trazia comigo. Para realizar a dança, seriam necessários os sons do xamã cantando e da percussão do chocalho. Outras sessões aconteceram, nas quais eu dançava uma média de três horas, três vezes na semana, com o som de uma gravação da música do "maraká". Nestas sessões, passei ainda a executar, ao som de outra gravação, o canto-dança do ritual xamanístico “tauva”, realizado só por mulheres. Essas gravações constituíram a partitura musical da performance, sobre a qual sobrepunha minha voz. Do movimento do corpo, dançando a coreografia no espaço e do movimento dos passos da dança das mulheres asuriní, de três a quatro horas ininterruptas, vieram outros movimentos que o corpo foi levado a fazer, não mais a dança delas, mas algo sem identificação que pedia outro som. Em busca de algo que preenchesse de sentido e de cinestesia o movimento que vinha da dança asuriní, mas não era mais ela, fui a uma loja de produtos artísticos de povos indígenas americanos que se localizava exatamente à frente da Tisch School, na Broadway. Eu conhecia essa loja, junto a uma galeria de arte de artistas nativos, pois freqüentava o Native American Indian Museum e lá soube de sua existência. Os dados da experiência da antropóloga vivendo nos Estados Unidos, determinada por seu interesse em etnologia indígena, certamente faziam parte do processo de "bricolage" na criação da performance. Estava ali, bem à minha mão, a possibilidade de encontrar um som. E encontrei: quando ouvi as mulheres cree, no canto que acompanha o solo masculino, com a percussão do tambor, não tive dúvida que era outra versão da mesma estrutura de música ritual de povos indígenas e, portanto, uma solução para dar continuidade à incorporação da personagem. Esse canto feminino é um grito aos meus ouvidos. E completava perfeitamente a dançacanto sem identificação.

Desde o começo do processo, sabia também que dançaria somente com os colares, mais as pulseiras e uma calça íntima. De um lado, seria como dançam atualmente as mulheres asuriní, mas, de outro, seria a maneira pela qual eu exporia meu corpo numa entrega, ou melhor, despojamento, perante a audiência de pesquisadores e antropólogos. Uma nudez que se inspirava em algumas 
performances que assisti em Nova Iorque, realizadas por mulheres, nas quais o erotismo se transforma, com a exclusão do "glamour" de peças íntimas decorativas, e em seu lugar o sentido de proteção se sobrepõe à conotação sexual ou sensual da nudez. Completariam a incorporação da personagem as unhas enormes e coloridas das mulheres afro-novaiorquinas, as quais me fascinavam pelo uso incondicional, fosse qual fosse a atividade por elas exercidas. E sandálias havaianas.

Graziela Rodrigues me dirigiu na fase final de criação. Tomou forma o grito das mulheres cree com o qual passei a interromper imediatamente o movimento da dança asuriní, substituído por uma posição estática. Somente uma expressão facial era realizada: a boca se abria ao máximo possível juntamente com o arregalar dos olhos. Os braços subiam ao máximo da altura possível numa tensão, a partir de cujo clímax braços e músculos da face passavam a relaxar, até o máximo possível do relaxamento. Em seguida, retornava à dança das mulheres asuriní e me dirigia à mesa dos palestrantes, onde colocava novamente a capa que deixara numa cadeira, no início da performance. Retiravame na seqüência e voltava à sala, terminada a música dos índios cree.

A dança foi realizada nas bordas da sala, em torno das cadeiras onde se sentava o público, situado então no centro do espaço da coreografia. Às vezes, fazia um gesto de convite à dança, com o braço e mãos. Num determinado momento, ao som da música do ritual asuriní "tauva”, só de mulheres, cuja dança é realizada em círculo, deixei o trajeto em torno do público e dancei num espaço sem as cadeiras. Voltei a contornar as cadeiras e o público, até o momento do canto das mulheres cree, quando estancava o movimento da dança, como já descrito.

Havia 15 pessoas participando do simpósio. Nos primeiros cinco minutos da performance, cujo tempo foram os 20 minutos estabelecidos para cada comunicação, um dos participantes se levantou e se retirou, depois de perguntar a uma das organizadoras até quando eu ficaria fazendo “aquilo”. Penso que é justamente a instauração de outro tempo, diferente da exposição oral convencional, que provocou nos presentes a reflexão sobre a forma como a performance suscitava inquietações que tentavam responder. Uma das observações feitas pelos participantes foi a de que a repetição do movimento, após um primeiro momento de identificação de uma dança, deixava em suspenso conteúdos que, não sendo expressos pelo código convencional da linguagem oral e científica, aguardariam a própria participação do público para sua enunciação. Para mim, como tive oportunidade de expor, respondendo à pergunta feita sobre a diferen- 
ça entre a "palavra” e a "performance”, o sentido de dançar envolvendo espacialmente as pessoas presentes e repetir o movimento por um certo tempo que certamente suscitaria a pergunta do desistente (até quando ela ficaria fazendo aquilo) era o de estar presente, compartilhar aquele momento de indagações, vivenciar esse encontro em torno de questões que nos colocávamos, o tempo suspenso da experiência coletiva de se compartilhar a reflexão, através de sensações, de laços de comunicação sensível, estética e cinestésica, como no ritual. À outra pergunta feita, se se tratava da busca de um estado de transe através do movimento repetitivo da dança, respondi que se poderia chamar assim o resultado pessoal da performance, considerando-se que ocorria sim a incorporação de uma personagem, de maneira semelhante à incorporação de outros seres nos rituais xamanísticos, por exemplo, ou à transformação experimentada pelos praticantes desses rituais, que os leva vivenciar outras dimensões cósmicas, o estado subjuntivo o "as if" da liminaridade definida por Turner (apud Schechner, 1985, p. 102).

Essa personagem, incorporada nesse contexto, trazia a experiência do antropólogo que coloca sua subjetividade, através de seu corpo, despido e travestido, "como se" estivesse naquele momento compartilhando a perplexidade a que se submete, quando experimenta sensível e sensorialmente a arte do "outro". Nesse campo de estudos das artes de povos nativos em confronto com a sociedade capitalista global, que conflitos vive o pesquisador? De que experiência sensível é feito seu conhecimento sobre essa realidade? Como essa experiência se encontra envolvida na produção desse conhecimento? Essas são algumas das questões que tento neste outro momento, da escrita e da reflexão teórica, formular. Na verdade, eu não as tinha antes. Na verdade, não sei se essas são as questões mais importantes para o trabalho proposto.

Meu objetivo foi de que houvesse tantas e diversas questões quanto cada um dos participantes pudesse se fazer, pois o sentido dessa forma artística é o sentido aberto que proporciona a criação de conteúdos particulares a cada espectador participante. Tenho, entretanto, uma certeza apenas, para concluir o ciclo que se iniciou em Nova Iorque, continuou em Campinas e foi apresentado em Santiago do Chile, na reunião científica que discutiu a arte e a arte do “outro": eu não poderia participar de outra maneira a não ser essa. Não poderia por ter sido estimulada pelo convite desafiador das organizadoras, por estar em momento de reclusão, fora de meu país, estimulada por outras "performances culturais", motivada a criar e compartilhar com os colegas antropólogos a criação de novas formas de conhecer, refletir e produzir conhecimento. Isto é, 
conhecer, refletir e produzir conhecimento sobre e a partir da experiência de convívio com povos indígenas, sobre e através de sua arte.

\section{Referências}

GEERTZ, Clifford. Local knowledge: further essays in interpretive Anthropology. New York: Basic Books, 1983.

MÜLlER, Regina Polo. Os Asuriní do Xingu, História e Arte. Campinas: Editora da Universidade Estadual de Campinas, 1990.

MÜLLER, Regina Polo. As representações sensíveis e a abordagem da antropologia estética. In: CONGRESO INTERNACIONAL DE CIENCIAS ANTROPOLÓGICAS Y ETNOLÓGICAS,13., 1993, México. Resúmenes CICAE: las dimensiones culturales y biológicas del cambio global. México:CICAE, 1993. p. 308-309.

MÜLLER, Regina Polo. O corpo em movimento e o espaço coreográfico: antropologia estética e análise do discurso no estudo de representações sensíveis. In: NIEMEYER, Ana Maria de; GODOI, Emília Pietrafesa de. Além dos territórios: um diálogo entre a etnologia indígena, os estudos rurais e os estudos urbanos. Campinas: Mercado de Letras: Departamento de Antropologia, IFCH, Unicamp, 1998. p. 271-286.

MÜLLER, Regina Polo. Yokastas: estudo antropológico de um processo de criação e encenação. O Percevejo, Rio de Janeiro: Unirio, n. 12, p. 182-204, 2003.

RODRIGUES, Graziela. Bailarino-Pesquisador-Intérprete, processo de formação. Rio de Janeiro: Funarte, 1997.

SCHECHNER, Richard. Environmental Theatre. New York: Hawthorn Books, 1973.

SCHECHNER, Richard. The End of Humanism. New York: Performing Arts Journal Publications, 1982.

SCHECHNER, Richard. Between Theater and Anthropology. Philadelphia: University of Pennsylvania Press, 1985.

SCHECHNER, Richard. From ritual to theater and back: the efficacyentertainment braid. In: SCHECHNER, Richard. Performance Theory. London: Routledge, 1988. p. 106-152. 
SCHECHNER, Richard. Environmental Theatre: an expanded new edition. New York: Applause, 1994.

SCHECHNER, Richard. Performance Studies, an introduction. London: Routledge, 2002.

TURNER, Victor W. O processo ritual: estrutura e antiestrutura. Petrópolis: Vozes, 1974.

TURNER, Victor W. From Ritual to theatre: the human seriousness of play. New York: Performance Arts Journal Publications, 1982.

TURNER, Victor W. The Anthropology of Performance. New York: PAJ Publications, 1988.

TURNER, Victor. Floresta de símbolos: aspectos do ritual ndembu. Niterói: EdUFF, 2005. 